\title{
ANALISIS PENGARUH HARMONISA TERHADAP KABEL 'NYA'
}

\author{
Erwin Dermawan ${ }^{1, *}$, Mushoffa Ali Firdaus ${ }^{2}$, Anwar Ilmar Ramadhan ${ }^{3}$ \\ ${ }^{1,2}$ Jurusan Teknik Elektro, Fakultas Teknik, Universitas Muhammadiyah Jakarta \\ ${ }^{3}$ Jurusan Teknik Mesin, Fakultas Teknik, Universitas Muhammadiyah Jakarta \\ Jl. Cempaka Putih Tengah No 27 Jakarta Pusat 10510 Indonesia \\ *Email: erwindermawan@yahoo.com
}

\begin{abstract}
ABSTRAK
Dengan semakin berkembangnya peralatan elektronik dan bertambah nya barang elektronik yang dipakai maka semakin besar pengaruh nya ke sistem kelistrikan. Karena akibat penggunaan peralatan elektronik ini akan menimbulkan distorsi pada sistem tenaga listrik. Hal ini akan menurunkan kualitas daya listrik karena arus yang terdistorsi tidak berbentuk gelombang sinusoidal murni, meskipun sumber tegangan yang dipakai pada saat itu berbentuk gelombang sinusoidal murni. Efek yang bersifat kontinu menyebabkan pemanasan dan adanya rugi daya pada penghantar. Hal ini disebabkan meningkatnya arus dari tembaga akibat meningkatnya frekuensi.
\end{abstract}

Kata Kunci : Harmonisa, distorsi gelombang, Beban Nonlinier, Rugi Daya, kabel

\begin{abstract}
With the development of electronic equipment and grow its electronics are used, the greater its influence to the electrical system. Because of the use of electronic equipment will cause distortion in the power system. This will reduce the quality of electrical power due to the current distorted not purely sinusoidal wave form, although the voltage source used at the time of pure sinusoidal wave shape. Securities that are continuous warming and the power losses in the conductor. This is due to the increasing flow of copper due to increased frequency.
\end{abstract}

Keywords: Harmonic, waveform distortion, Nonlinear Load, Power Loss, cable

\section{PENDAHULUAN}

Tujuan utama dalam sistem tenaga listrik adalah dapat memasok daya sesuai dengan kebutuhan yang riil. Untuk dapat memasok daya sesuai dengan kebutuhan nya maka pemilihan penghantar untuk sebuah sistem tenaga listrik harus dilakukan perhitungan dengan matang, karena penghantar ini harus mengalirkan daya secara konstan dengan rugi rugi yang di akibatkan nya seminimal mungkin.

Adanya distorsi bentuk gelombang arus dan tegangan pada sistem tenaga listrik, sudah ada sejak dikenalnya keberadaan sistem tenaga AC
(Alternating Current). Saat ini, peralatan yang menimbulkan harmonik telah berkembang dengan pesat baik dari segi kualitas maupun kuantitas produknya. Peralatan elektronik banyak menggunakan bahan semi konduktor seperti dioda, silicon controlled rectifier (SCR), transistor dan peralatan semi konduktor lainnya. Bahan semi konduktor inilah yang menyebabkan terjadinya distorsi arus dan tegangan, karena antara tegangan yang masuk pada sistem tidak sebanding dengan tegangan keluarannya atau dengan kata lain mengalami distorsi. 
Harmonisa pada dasarnya adalah sebuah komponen sinusoidal dari sebuah bentuk gelombang periodik yang frekuensinya merupakan perkalian bilangan bulat dengan frekuensi dasarnya. Frekuensi dari gelombang periodik tersebut disebut frekuensi harmonisa yang timbul pada bentuk gelombang aslinya, sedangkan bilangan bulat pengali frekuensi dasar adalah angka urutan dari harmonisa tersebut. (B.Hermawanto, 1996: 9).

Sistem tenaga listrik yang terhubung dengan beban nonlinear akan menghasilkan arus harmonik yang menyebabkan distorsi gelombang arus dan tegangan. Tegangan harmonik juga dapat menyebabkan kenaikan arus pada penghantar netral sehingga mengakibatkan kenaikan rugi-rugi daya. Harmonik dapat menyebabkan pemutusan beban yang sensitif, penurunan keakuratan alat ukur, kegagalan kapasitor tenaga, serta menungkatnya rugi rugi pada saluran, rugi-rugi ini disebabkan oleh meningkatnya arus rms dan meningkatnya tahanan penghantar akibat frekuensi harmonisa yang lebih tinggi dari frekuensi fundamental dimana efek yang ditimbulkan dikenal sebagai efek kulit ( skin effect) dan efek kedekatan (proximity effect).

Untuk menghindari hal tersebut, perlu dilakukan prediksi untuk memperkirakan kondisi pengoperasian dengan cara analisis aliran beban pada sistem tenaga listrik saat kondisi normal. Kemudian dilakukan analisis harmonik dengan menambahkan beban nonlinear sebagai sumber harmonik.

\section{Kabel Penyalur Daya Listrik Pengertian Kabel}

Secara umum pengertian kabel adalah media penghantar tenaga listrik dari sumber tegangan listrik keperalatan yang menggunakan tenaga listrik atau menghubungkan suatu peralatan listrik ke peralatan listrik lainnya. Bahan dari kabel ini beraneka ragam, khusus sebagai pengantar arus listrik, umumnya terbuat dari tembaga dan umumnya dilapisi dengan pelindung. Selain tembaga, ada juga kabel yang terbuat dari serat optik, yang disebut dengan fiber optic cable. Namun dalam hal ini yang akan kita bahas adalah kabel yang berfungsi untuk menghantarkan energi listrik. Dalam penyaluran tenaga listrik, ada banyak faktor yang mempengaruhi baik atau tidaknya penyaluran tersebut.

\section{Harmonisa}

Harmonisa atau harmonik adalah gangguan yang terjadi pada sistem distribusi tenaga listrik akibat terjadinya distorsi gelombang arus dan tegangan [Nanan Tribuana dan Wanhar, 1999]. Distorsi gelombang arus dan tegangan ini disebabkan adanya pembentukan gelombanggelombang dengan frekuensi kelipatan bulat dengan frekuensi dasarnya (fundamental). Hal ini disebut frekuensi harmonik yang timbul pada bentuk gelombang aslinya sedangkan bilangan bulat pengali frekuensi dasar disebut angka urutan harmonik [Jon Marjuni Kadang, 2006].

Harmonisa juga biasanya didefinisakan sebagai distorsi yang bersifat periodik serta steady state pada gelombang arus dan gelombang tegangan yang terjadi dalam sistem tenaga [Gary W Chang dan Paulo F. Ribeiro, ---].

Pasokan arus dan tegangan dari sistem transmisi umumnya berupa gelombang sinusoidal murni, namun dengan keanekaragaman beban saat ini, pasokan tegangan dan arus yang semula sinusoidal murni dapat terdistorsi. Cacat gelombang arus atau tegangan ini disebut cacat harmonik, cacat gelombang arus disebabkan oleh beban yang nonlinier seperti Lampu (selain lampu pijar), Automatic/Variable speed drive (ASD), DC-drive, Power rectifier, Pemanas Induksi, Furnaces, UPS, Computer dan lain-lain. Arus harmonik yang melalui impedansi dari sistem akan dapat menyebabkan tegangan harmonik pada titik beban tersebut [Jemjem Kurnaen dan Sidik Prasetyo, ---].

Dan gambar berikut ini memperlihatkan gelombang sinus yang terdistorsi oleh harmonik ke 3.

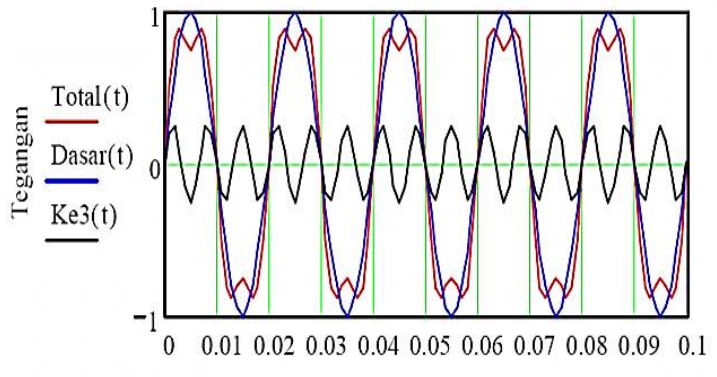

$\mathrm{t}$

waktu (detik)

Gambar 1. Gelombang Harmonik [Jemjem Kurnen dan Sidik Prasetyo, ---]

\section{Sumber-Sumber Harmonisa}

Dalam sistem tenaga listrik dikenal dua jenis beban yaitu beban linier dan beban nonlinier. Beban linier adalah beban yang memberikan bentuk gelombang keluaran yang linier artinya arus yang mengalir sebanding dengan impedensi dan perubahan tegangan. Sedangkan beban non linier adalah bentuk gelombang keluarannya tidak sebanding dengan tegangan dalam setiap setengan siklus sehingga bentuk gelombang arus maupun tegangan keluarannya tidak sama dengan gelombang masukannya (mengalami distorsi). Beban nonlinier yang umumnya merupakan peralatan elektronik yang didalamnya banyak terdapat komponen semikonduktor, dalam proses kerjanya berlaku sebagai saklar yang bekerja pada setiap siklus gelombang dari sumber tegangan. Proses kerja ini akan menghasilkan gangguan atau 
distorsi gelombang arus yang tidak sinusoidal [Nanan Tribuana dan Wanhar, 1999].

\section{Standar Harmonisa}

Standar harmonisa berdasarkan stardar IEEE 519-1992. Ada dua kriteria yang digunakan untuk mengevaluasi distorsi harmonisa. Yang pertama adalah batasan untuk harmonisa arus. Dan yang kedua adalah batasan untuk harmonisa tegangan. Untuk standar harmonisa arus, ditentukan oleh rasio Isc/ $\mathrm{I}_{\mathrm{L}}$. Isc adalah arus hubung singkat yang ada pada PCC (Point of Common Coupling), sedangkan $\mathrm{I}_{\mathrm{L}}$ adalah arus beban fundamental nominal. Sedangkan untuk standar harmonisa tegangan ditentukan oleh tegangan sistem yang dipakai. (Ned Mohan, 1994).

Standar harmonisa arus dapat dilihat pada Tabel 1. sedangkan standar harmonisa tegangan dapat dilihat pada Tabel 2.

Tabel 1. Maximum Harmonics Current Distortion

\begin{tabular}{|c|c|c|c|c|c|c|}
\hline \multirow[b]{2}{*}{ Isc /IL } & \multicolumn{5}{|c|}{ Harmonic Orde (Odd Harmonic) } & \multirow{3}{*}{$\begin{array}{l}\text { THD } \\
(\%)\end{array}$} \\
\hline & $<11$ & $11=<h<23$ & $17=<\mathrm{h}<23$ & $23=<h<35$ & $35=<h$ & \\
\hline & & & & & & \\
\hline$<20$ & 4 & 2 & 1.5 & 0.6 & 0.3 & 5 \\
\hline $20-50$ & 7 & 3.5 & 2.5 & 1 & 0.5 & 8 \\
\hline $50-100$ & 10 & 4.5 & 4 & 1.5 & 0.7 & 12 \\
\hline $100-1000$ & 12 & 5.5 & 5 & 2 & 1 & 15 \\
\hline$>1000$ & 15 & 7 & 6 & 2.5 & 1.4 & 20 \\
\hline
\end{tabular}

Dimana :

Isc $=$ Arus Maksimum Hubung Singkat pada PCC ( Point of Common Coupling )

$\mathrm{IL}=$ Arus Beban Maksimum ( fundamental frequency ) pada PCC.

(Ned Mohan. 1994)

Tabel 2. Maximum Harmonics Voltage Distortion

\begin{tabular}{|c|c|c|c|}
\hline \multicolumn{4}{|c|}{ Maximum Voltage Distortion } \\
\hline \multirow{2}{*}{ Maximum Distortion } & \multicolumn{3}{|c|}{ System Voltage } \\
\cline { 2 - 5 } & Below 69 kV & $69-138 \mathrm{kV}$ & $>138$ \\
\hline Individual Harmonics (\%) & 3 & 1.5 & 1 \\
\hline Total Harmonics (\%) & 5 & 2.5 & 1.5 \\
\hline
\end{tabular}

\section{Rugi Daya Pada Penghantar}

Rugi-rugi pada penghantar tidak dapat dihilangkan karena setiap penghantar mempunyai nilai tahanan jenis yang menyebabkan adanya daya terserap pada penghantar.

Nilai rugi-rugi pada penghantar dapat dihitung dengan rumus :

$P_{\text {rugi-rugi }}=\left(I_{1}\right)^{2} \times R$

$P_{\text {rugi-rugi(harmonisa })}=\left(I_{\text {rms }}\right)^{2} \times R \ldots$.
Losses $(\%)=\frac{P_{\text {rugi-rugi harmonisa }} \text { Prugi-rugi }_{\text {rug }}}{\text { Prugi-rugiharmonisa }_{\text {rath }}} \times 100 \%$

Dimana R dapat dihitung dengan rumus :

$R=\not p \times \frac{L}{a}$

Dengan:

$R=$ Hambatan kabel dalam ohm

$\bar{P}=$ Tahanan Jenis Tembaga $0.01741 \Omega . \mathrm{mm}^{2} / \mathrm{m}$

$\mathrm{a}=$ Luas Penghantar dalam $\mathrm{mm}^{2}$

$\mathrm{L}=$ Panjang penghantar, dalam $\mathrm{m}$

\section{ANALISA DAN PENGAMBILAN DATA Diagram Alir}

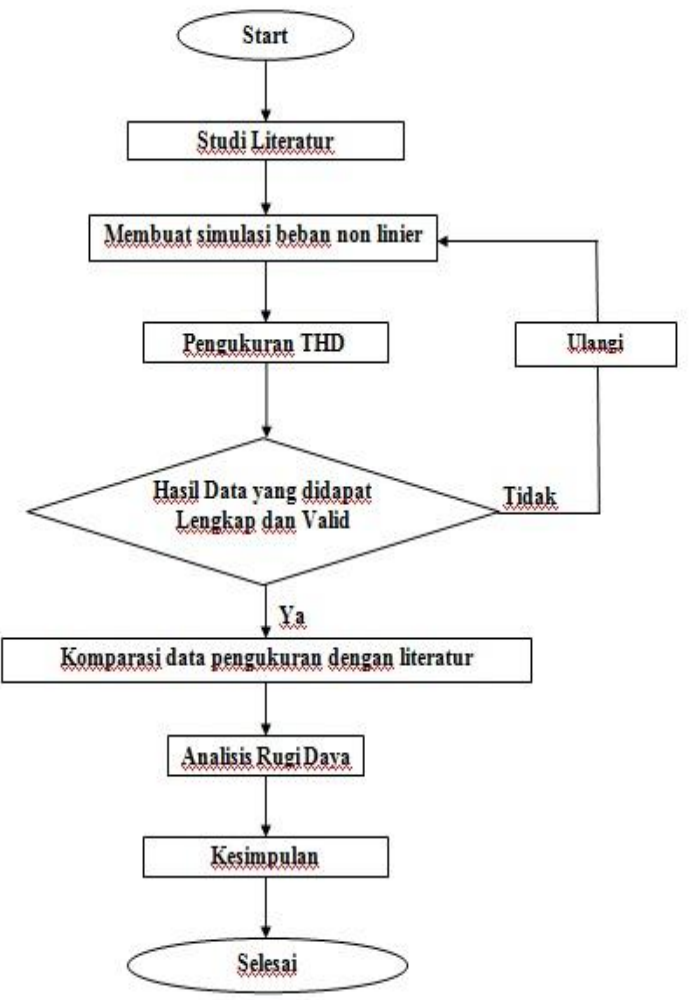

Gambar 2. Diagram Alir Tahap Pengambilan Data

Alat Ukur dan Beban Harmonik

Alat Ukur :

Power Harmonic Analyzer Hioki PW 3198

Beban-beban Harmonik :

1. Motor Listrik

2. Laptop

3. Charger Handphone

4. Speaker Aktiv

5. Lampu Hemat Energi 


\section{Diagram Satu Garis Pengukuran}

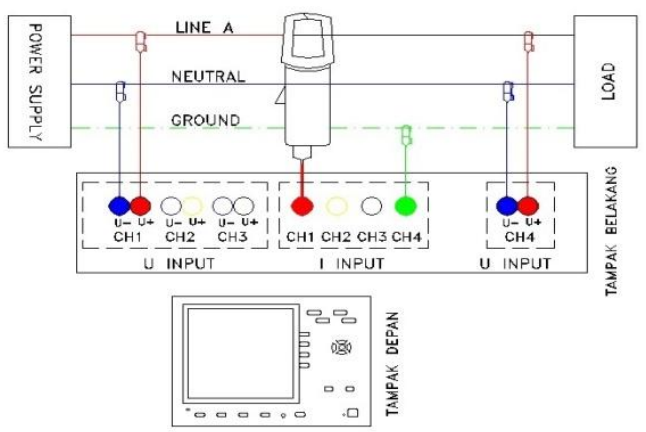

Gambar 3. Diagram Satu Garis untuk Pengukuran Beban Satu Fasa

\section{Tujuan Analisa}

Tujuan dari analisa hasil pengukuran kandungan harmonisa pada macam-macam beban yang telah dipilih adalah :

1. Mengukur besarnya kandungan harmonisa pada beban peralatan elektronik rumah tangga

2. Mengetahui dan membandingkan penambahan arus dan losses pada penghantar dengan panjang dan luas penampang yang berbeda.

\section{Hasil Pengukuran}

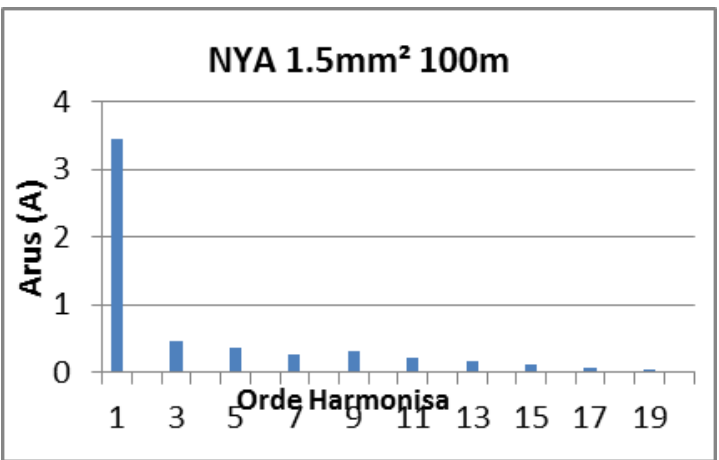

Gambar 4. Grafik THD I pada NYA $1.5 \mathrm{~mm}^{2}$ $100 \mathrm{mtr}$

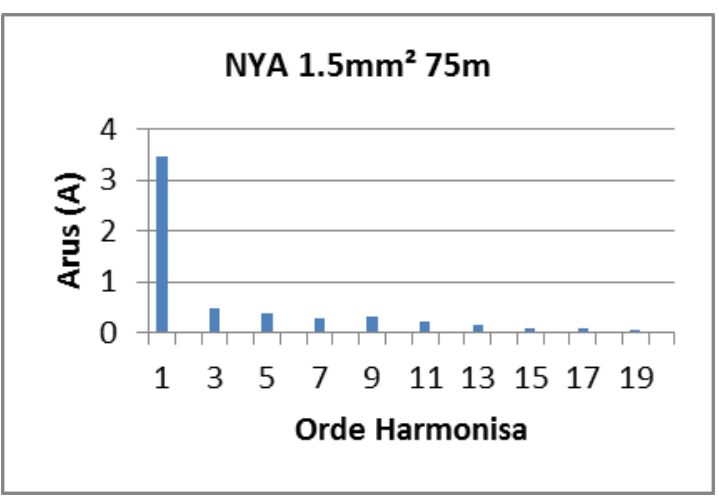

Gambar 5. Grafik THD I pada NYA $1.5 \mathrm{~mm}^{2} 75 \mathrm{mtr}$

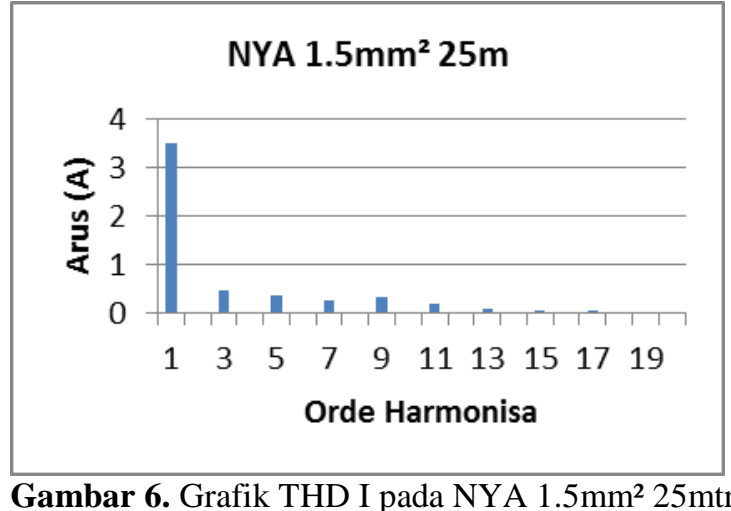

Gambar 6. Grafik THD I pada NYA $1.5 \mathrm{~mm}^{2} 25 \mathrm{mtr}$

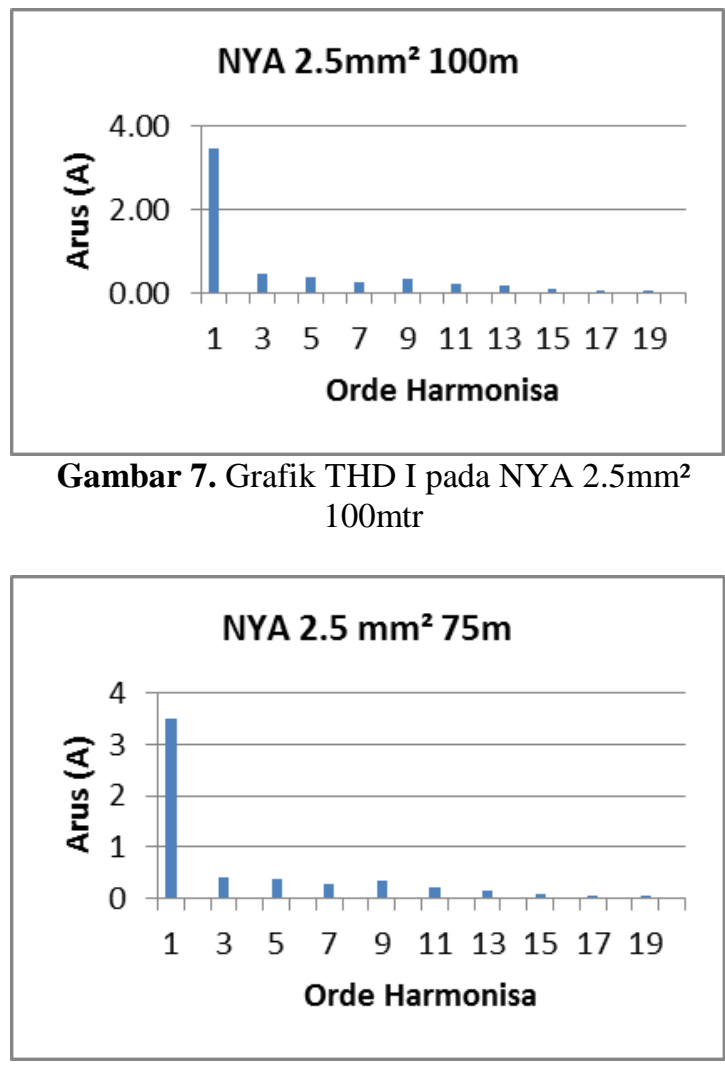

Gambar 8. Grafik THD I pada NYA $2.5 \mathrm{~mm}^{2} 75 \mathrm{mtr}$

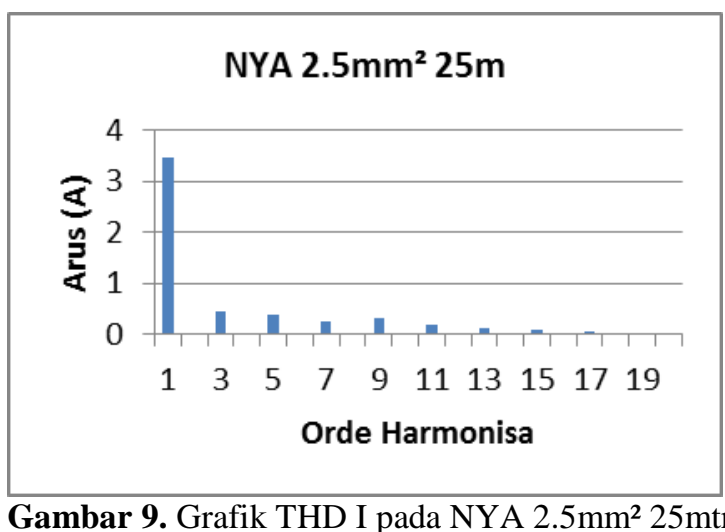

Gambar 9. Grafik THD I pada NYA $2.5 \mathrm{~mm}^{2} 25 \mathrm{mtr}$ 
Tabel 3. Tabel hasil analisa harmonisa terhadap kabel NYA

\begin{tabular}{|c|c|c|c|c|}
\hline NO & $\begin{array}{c}\text { UKURAN } \\
\text { KABEL }\end{array}$ & $\begin{array}{c}\text { PANJANG } \\
\text { KABEL (M) }\end{array}$ & $\begin{array}{c}\text { LOSSE } \\
\text { S (\%) }\end{array}$ & $\begin{array}{c}\text { RUGI } \\
\text { DAYA } \\
\text { (Watt) }\end{array}$ \\
\hline 1 & $\begin{array}{c}\text { NYA } \\
1.5 \mathrm{~mm}^{2}\end{array}$ & 100 & 7.65 & 1.13 \\
\hline 2 & $\begin{array}{c}\text { NYA } \\
1.5 \mathrm{~mm}^{2}\end{array}$ & 75 & 4.83 & 0.52 \\
\hline 3 & $\begin{array}{c}\text { NYA } \\
1.5 \mathrm{~mm}^{2}\end{array}$ & 25 & 4.43 & 0.16 \\
\hline 4 & $\begin{array}{c}\text { NYA } \\
2.5 \mathrm{~mm}^{2}\end{array}$ & 100 & 4.68 & 0.405 \\
\hline 5 & $\begin{array}{c}\text { NYA } \\
2.5 \mathrm{~mm}^{2}\end{array}$ & 75 & 4.47 & 0.294 \\
\hline 6 & $\begin{array}{c}\text { NYA } \\
2.5 \mathrm{~mm}^{2}\end{array}$ & 25 & 4.26 & 0.092 \\
\hline
\end{tabular}

\section{Grafik Persentase Losses NYA} $1.5 \mathrm{~mm}^{2}$

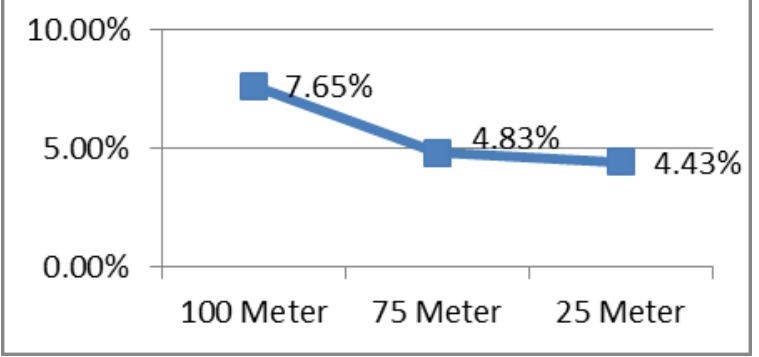

Gambar 10. Grafik Persentase Losses NYA $1.5 \mathrm{~mm}^{2}$

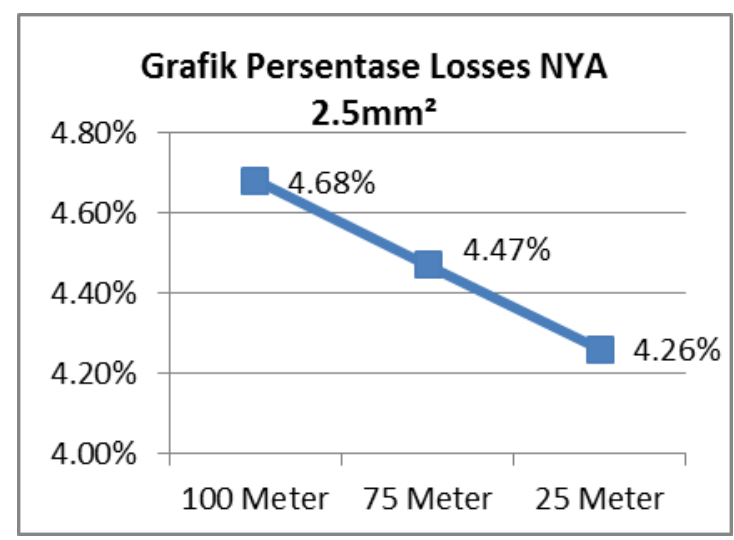

Gambar 11. Grafik Persentase Losses NYA

$$
2.5 \mathrm{~mm}^{2}
$$

Dari Grafik diatas terlihat bahwa harmonisa menyebabkan penambahan arus rms pada bebanbeban harmonik $\left(\mathrm{I}_{\mathrm{rms}}>\mathrm{I}_{1}\right)$, yang mengakibatkan losses pada penghantar. Melalui contoh beban yang diajukan oleh penulis, dengan beban yang sama namun berbeda luas penghantar dan panjang penghantar nya terjadi perbedaan persentase losses nya.
Pada penghantar NYA $1.5 \mathrm{~mm}^{2}$ dengan panjang 100 meter dengan nilai persentase $7,65 \%$. Pada kabel yang sama dengan panjang 75 meter persentase loses nya menurun menjadi $4,83 \%$, dan pada panjang 25 meter persantase loses nya di $4,43 \%$

Pada penghantar NYA $2.5 \mathrm{~mm}^{2}$ dengan panjang 100 meter dengan nilai persentase $4,68 \%$. Pada kabel yang sama dengan panjang 75 meter persentase loses nya menurun menjadi $4,47 \%$, dan pada panjang 25 meter persantase loses nya di $4,26 \%$

Dari hasil analisa tersebut dampak dari beban-beban harmonik dimana rugi-rugi daya pada penghantar lebih besar ditimbulkan oleh bebanbeban harmonik, dan kenaikan rugi daya tidak diikuti dengan kelipatan penambahan panjang penghantar, penggunaan penghantar yang lebih besar luas penampangnya akan mengurangi rugi daya (losses).

\section{KESIMPULAN}

Berdasarkan hasil pengukuran yang telah dilakukan terhadap Analisis Pengaruh Harmonisa Terhadap Kabel NYA, maka dapat disimpulkan bebarapa hal yaitu :

a. Peralatan elektronik cenderung menimbulkan harmonisa serta pengaruh panjang penghantar dapat menimbulkan rugi rugi daya pada penghantar. Seiring timbulnya harmonisa pada sisi arus yang tidak sesuai standar IEE 519-1992 bisa mengakibatkan panas yang berlebih pada penghantar dan yang paling buruk bisa mengakibatkan terbakar nya penghantar.

b. Rugi daya tertinggi terjadi pada luas penampang $1,5 \mathrm{~mm}^{2}$ panjang 100 meter yaitu 1,13 Watt. Sedangkan pada penghantar $2.5 \mathrm{~mm}^{2}$ dengan panjang 100 meter rugi daya nya 0,45 Watt. Dapat di simpulkan bahwa semakin besar luas penghantar dapat mengurangi losses daya.

\section{DAFTAR PUSTAKA}

W.Z.Gandhare, K.D. Patil, "Effec of Harmonics On Power Loss In XLPE Cables", Energy And Power Engineering Journal (ACIJ), vol. 5, no. 1235-1239, July 2013.

I Wayan Sudiartha, “Analisis Pengaruh Harmonisa Terhadap Rugi Rugi Daya Pada Penghantar, Politeknik Negeri Bali, November, 2013

"catalog Industrial cable wire". Di akses dari http://www.kabelindo.co.id pada tanggal 1 November 2014

Fransisco.C. De La Rosa. Harmonics And Power System, New York : Taylor and Francis, 2006

Adrianus. Pengaruh Jenis kabel. Fakultas Teknik UI. 2008 
MK, Trisno, Bambang,. Kabel Dan Teknik Penyambungan

http://muhammadluthfibaidhowi.blogspot.com/201 4/02/jenis-jenis-kabel-listrik-instalasi.html diakses tanggal 11 November 2014. 